\title{
Why do UK academics become Associate Deans and what are their future career plans?
}

Article

Accepted Version

Updated accepted version

Floyd, A. and Preston, D. (2019) Why do UK academics become Associate Deans and what are their future career plans? Journal of Higher Education Policy and Management, 41 (4). pp. 430-443. ISSN 1469-9508 doi:

https://doi.org/10.1080/1360080x.2019.1625220 Available at https://centaur.reading.ac.uk/83126/

It is advisable to refer to the publisher's version if you intend to cite from the work. See Guidance on citing.

To link to this article DOI: http://dx.doi.org/10.1080/1360080x.2019.1625220

Publisher: Taylor \&Francis

All outputs in CentAUR are protected by Intellectual Property Rights law, including copyright law. Copyright and IPR is retained by the creators or other copyright holders. Terms and conditions for use of this material are defined in the End User Agreement.

www.reading.ac.uk/centaur 
Central Archive at the University of Reading

Reading's research outputs online 
Why do UK academics become Associate Deans and what are their future career plans?

\author{
Alan Floyd ${ }^{\mathrm{a} *}$ and Diane Preston ${ }^{\mathrm{b}}$ \\ ${ }^{a}$ Institute of Education, University of Reading, UK; ${ }^{b}$ Open University Business School, \\ Milton Keynes, UK \\ *corresponding author \\ Dr Alan Floyd, Institute of Education, University of Reading, RG1 5EX, UK \\ E: alan.floyd@reading.ac.uk
}




\title{
Why do UK academics become Associate Deans and what are their future career plans?
}

\author{
The role and number of Associate Dean posts in UK universities has grown \\ considerably in recent years. Despite this, relatively little is known about the \\ reasons why individuals take on such roles and how it fits into their career \\ trajectories. The purpose of this article is to explore these issues by drawing on \\ data from the first national study of Associate Deans in the UK. Adopting a two- \\ staged mixed methods approach, data were collected from semi-structured \\ interviews ( $n=15)$ and an online survey of Associate Deans $(n=172)$. The findings \\ suggest that academics take on the role for a number of reasons such as the \\ challenge of working across the University, making a difference to staff and \\ students, or being asked to take it on by a senior member of staff. It is argued that \\ these Associate Dean roles are part of new and emerging academic career \\ pathways within the higher education sector.
}

Keywords: academic leader, career trajectories, academic career capital

\section{Introduction}

It has previously been argued that the notion of a traditional academic career is changing due to a number of factors such as internationalisation, differences in working conditions, an increase in the number of fixed term contracts, increased accountability within the sector, and rapidly changing research horizons (Floyd, 2012; Jepsen et al., 2014; Petersen, Riccaboni, Stanley, \& Pammolli, 2012). These factors have led to the academic career path being 'refashioned' (Angervall, Gustafsson, \& Silfver, 2018, p. 1095). It has also been argued that in order to fully understand an academic's career decisions in such a changing environment, especially those who take on leadership roles within an organisation, it is necessary to explore the different socialisation experiences they encounter during their career journey (Floyd, 2012). To help understand how taking on these leadership roles may affect an academic's future career trajectory, an earlier article published in this journal proposed the concepts of internal and external 
academic career capital (Floyd \& Dimmock, 2011). This theoretical thinking, which draws on Bourdieu's concepts of field and capital (Bourdieu, 1984, 1988, 1998), suggests that academics develop their careers within a career field in which particular sorts of capital are valued over others. This academic career capital has both internal and external dimensions, with internal aspects being linked to someone's role and status within their organisation and external aspects linked to their outward facing achievements such as research publications and national and international networks (Floyd \& Dimmock, 2011).

While these issues were previously explored through the role of the academic head of department, the purpose of this paper is to extend this work and investigate them through the perspectives of Associate Deans by drawing on data from a Leadership Foundation funded study which examined the role within UK Universities. In the UK, Associate Deans are perceived as middle leaders, positioned above department heads and below more senior leaders such as Faculty Deans (Floyd \& Preston, 2017; Preston \& Floyd, 2016). Rather than just supporting the Dean however, as their title might suggest, they often have quite distinct portfolios based on, for example, research, student experience, or international engagement.

Although the number of Associate Deans in university leadership structures appears to be on the rise, it is a role that is under-researched and not well understood with previous work relying on small scale studies (see, for example, Pepper \& Giles, 2015; Preston \& Price, 2012). The exception to this is a recently published paper based on a national survey of Associate Deans $(\mathrm{n}=527)$ undertaken in the USA (Sayler, Pedersen, Smith, \& Cutright, 2017) which found that most surveyed were appointed internally, with the majority being asked by their Dean to take on the role. Additionally, 
they found that most were responsible for managing academics, administrative services and curricular issues.

In contrast, it appears from previous work that we have published elsewhere that Associate Deans in the UK tend to be involved with more strategic rather than operational activities, with many working on cross University and inter-disciplinary project type work rather than leading large groups of staff or holding big budgets (Floyd \& Preston, 2017). It also appears that academics who take on these roles do not receive enough training and that most rely on informal networks for support (Preston \& Floyd, 2016), mirroring findings from the US study (Sayler et al., 2017). These facts will undoubtedly impact on their day to day professional experiences and subsequent career decisions and raise important questions, namely, why and how do academics become Associate Deans? And how does taking on this role affect their future careers? Thus, the research questions addressed in this paper are:

(1) What are the circumstances that lead to UK academics becoming Associate Deans?

(2) How do academics see their position as Associate Dean influencing their career?

By drawing on data from the first National Study of Associate Deans to be undertaken in the UK, and using a theoretical framework based on the concept of academic career capital, this paper offers a significant and original contribution to knowledge. As empirical studies in this area are rare (van Balen, van Arensbergenb, van der Weijdenc, \& van den Besselaar, 2012), the article offers new theoretical insights into modern academic career trajectories as well as highlighting some key implications for policy makers, senior leaders and researchers in relation to career development needs and 
succession planning within the sector.

This paper is organised into five sections. The first outlines the study's theoretical framework. The second gives an overview of the data collection methods used, while section three presents the findings and analysis. Following the discussion, the final section outlines the implications of the research for theory, practice and further research.

\section{Theoretical Framework}

As outlined earlier, we use a theoretical framework based on the notion of internal and external academic career capital (Floyd \& Dimmock, 2011). This concept centres on the fact that an academic's career and their career decisions take place within a career field (Bourdieu, 1984, 1988, 1998) and academic career trajectories are influenced by what is perceived as important capital within that field, both within an institution (internal) and externally (for example being able to move to another institution). For academics, valued career capital traditionally relates to research outputs and income generation (Court, 1999; Liénard, Achakulvisut, Acuna, \& David, 2018; Petersen et al., 2014), with the picture being similar with those who take on head of department positions (Floyd, 2013; Floyd \& Dimmock, 2011). It has been found that such people, because they are unable to continue properly with their research and publications when in a busy and complex management role, may be able to develop internal career capital within the same institution (related to managerial experience), but can suffer a potential loss of external career capital (related to research outputs and external grant capture) and so may find themselves not being able to apply for key posts outside of their organisation. However, more recently it has been argued that our current understanding of modern academic work is limited and that we need to adopt a more holistic picture of what 
being an academic is, which would entail moving away from seeing academic contributions as just being linked to research (Rosewell \& Ashwin, 2018, p. 9):

As universities strive to widen participation and retention of academic staff as well as students from different backgrounds, it would seem reasonable to highlight the importance for universities to move away from a 'one-size-fits-all' approach to being an academic, and measures of success, such as the importance placed on research publications; and the potential exclusion of other criteria, such as success in teaching and providing a contribution to the lives of students and/or to society, and other meanings of being an academic that do not centre on research.

Similar calls have been made for academic careers in areas where the demand to do research may sit uncomfortably with those who identify as teachers, such as in medical education (Hu et al., 2015). As the higher education landscape rapidly changes and evolves, the above thinking has implications for both individuals and institutions, especially around the notion of academic career trajectories and recruitment and retention, and therefore helps to frame the data and analysis that are presented here.

\section{Methods}

We used an exploratory, sequential two staged mixed methods design (Cresswell, 2014) where qualitative data are gathered and analysed first, before quantitative data are collected from a larger sample size. In stage one we interviewed 15 Associate Deans from five different institutions in England using a stratified purposive sampling approach (Bryman, 2012). Thus, the sample contained male $(n=11)$ and female $(n=4)$ staff with a range of ages, levels of experience and discipline backgrounds. Table 1 shows the interview participants together with the institution type, faculty and role focus. To ensure anonymity for respondents, pseudonyms have been used throughout and subject disciplines and faculties have been grouped into the generic terms of social 
sciences, arts and humanities, and sciences.

Table 1: Interview participants

\begin{tabular}{llll}
\hline Pseudonym & Institution & Faculty & Role Focus \\
\hline Bruce & Post-1992 & Social Sciences & Strategy and Development \\
Isobel & Post-1992 & Social Sciences & Quality Enhancement \\
Laura & Post-1992 & Sciences & Student Experience \\
Michael & Post-1992 & Social Sciences & Student Experience \\
Richard & Post-1992 & Social Sciences & Quality Enhancement \\
Steven & Post-1992 & Sciences & Student Experience \\
Tony & Post-1992 & Sciences & Operation and Performance \\
William & Post-1992 & Arts and Humanities & Quality Enhancement \\
\hline Alex & Pre-1992 & Sciences & Teaching and Learning \\
Chris & Pre-1992 & Arts and Humanities & Teaching and Learning \\
Claire & Pre-1992 & Social Sciences & Research \\
David & Pre-1992 & Social Sciences & Teaching and Learning \\
Peter & Pre-1992 & Sciences & Teaching and Learning \\
Phil & Pre-1992 & Sciences & Research \\
Whitney & Pre-1992 & Arts and Humanities & Teaching and Learning \\
\hline
\end{tabular}

Before commencing data collection, ethics approval was sought from both authors' institutions. After that was granted, each participant was then approached via email having been identified as an Associate Dean via institutional websites. A detailed information sheet was attached to each invitation outlining the process and risks and benefits of participation. Once they had agreed to participate, the interviewees were asked to sign a consent form which outlined their right to withdraw and gave consent for the interview to be recorded. Interviews were undertaken in person and via Skype (by both researchers) with each interview typically taking about an hour. These data sets were transcribed and entered into Nvivo software package and then analysed by both researchers using coding techniques outlined by Lichtman (2013). This included each researcher coding each transcript separately and then grouping these together to form initial themes. The researchers then came together to discuss and refine these emerging themes and relate these to the study's conceptual framework, thus allowing for interresearcher agreement. An example of some of the codes and themes generated by 
iterative this process is shown in Table 2.

Table 2: Example of thematic analysis

\begin{tabular}{l|l|l}
\hline Initial Codes & Themes & Concepts \\
\hline $\begin{array}{l}\text { Creeping into leadership } \\
\text { Learning to lead }\end{array}$ & Prior leadership experience & $\begin{array}{l}\text { Identity shifts - Becoming academic managers } \\
\text { (Winter, 2009) }\end{array}$ \\
$\begin{array}{l}\text { Entering the black hole } \\
\text { Returning to the ranks }\end{array}$ & Career plans \\
Moving on up & & $\begin{array}{l}\text { Internal and external career capital } \\
\text { (Floyd \& Dimmock, 2011) }\end{array}$ \\
\hline
\end{tabular}

In stage two, we developed an online survey (using SurveyMonkey) based on the themes that emerged from the interview process described above. The initial survey was peer reviewed and then piloted with a group of Associate Deans, with several changes to wording being made during this process. The survey consisted of 5 main sections: personal and role information (including reasons for taking on the role); purpose of role and organisational structure (including budget and staff management information); role preparation and training; experiences of being in the role (opportunities and challenges); and future career plans. The final survey contained 39 questions, some of which were closed multiple choice items, some used Likert scales and others were open-ended.

Then we sent out a link to the survey to 472 Associates Deans throughout England, Scotland and Wales (with names identified from institutional websites). Informed consent was requested on the first page of the survey. In total 172 Associate Deans completed the survey (36 per cent response rate); this included 71 female Associate Deans (42 per cent) and 97 male Associate Deans (58 per cent). The survey sample by academic discipline and university type is shown in Table 3. All the Associate Deans in this study were in full time roles, although the type of contract they were on differed with some being on temporary fixed term contracts and others in a permanent positions; these differences are explored elsewhere (see Preston \& Floyd, 2016). Additionally, some were also purported to be given a set amount of 'protected' 
time in order to continue with their research and teaching (for example, one day a week) however our findings suggest that this idea was very difficult to implement in practice given the demands of the role. This issue will be discussed later in this article.

The quantitative survey data were cross tabulated to compare data from those who were Associate Deans in 'traditional' pre-1992 Universities with those from 'new' post-1992 Universities. In the UK, former polytechnics and colleges of higher education were given university status in 1992 and this distinction is often used because of the perceived cultural differences between the two types of Universities: pre-1992 institutions are seen as more research focused than post-1992 institutions, which are seen as more teaching focused.

Table 3: Survey sample - academic discipline

\begin{tabular}{lllllll}
\hline Discipline & \multicolumn{2}{l}{ Pre-1992 } & \multicolumn{2}{l}{ Post-1992 } & \multicolumn{2}{l}{ Total } \\
\hline & $\mathbf{n}$ & $\mathbf{\%}$ & $\mathbf{n}$ & $\mathbf{\%}$ & $\mathbf{n}$ & \% \\
Life Sciences/Medicine & 27 & 26 & 8 & 12 & 35 & 20 \\
Business & 12 & 12 & 20 & 29 & 32 & 19 \\
Social Sciences & 19 & 18 & 10 & 14 & 29 & 17 \\
Physical/Natural Sciences & 13 & 13 & 8 & 12 & 21 & 12 \\
Humanities & 13 & 13 & 3 & 4 & 16 & 9 \\
Arts & 5 & 5 & 3 & 4 & 8 & 5 \\
Other & 14 & 13 & 17 & 25 & 31 & 18 \\
Total & 103 & 100 & 69 & 100 & 172 & 100 \\
\hline
\end{tabular}

\section{Findings}

\section{Prior leadership experience}

All the interviewees in our study had held prior leadership roles before taking on the position of Associate Dean including head of department, director of teaching and learning and director of research. Taking on these roles and their associated experiences do not appear to have been carefully planned out, but instead were part of a common 'creep' into leadership roles during their careers, all of which had been impacted by institutional restructuring. As Bruce described: 
And I sort of ... you were asking about the career... So, I sort of crept up the ladder if you like. I did a stint as an assistant director undergraduate programmes, went back to being department head. Then moved in for a three- year stint in our commercial division, and then the restructuring that went on at the end of 2010, I think it was, I applied for the role of associate dean, strategy and development, and got it and that's where I am now. (Bruce, post-1992 University)

And Isobel said:

I came to this university in 1999 having worked previously at another institution. And I came as a senior lecturer, primarily to lead an undergraduate programme. Then after that I did a principal lecturer job working with external businesses because they were doing a major review, so they needed somebody in-house. Then there were some structural changes and I was asked to act up as head of academic affairs for two years and then that sort of translated into a big restructure across the whole university which introduced Associate Deans and at that point I became associate dean for quality and practice. (Isobel, post-1992 University)

The survey results also showed that the participants had held a variety of previous leadership and management roles (see Table 4). In this question, participants were asked to tick all options that applied. From the open ended 'other' option 31 other former roles were identified across both types of institutions which included School Director of Admissions, Director of Undergraduate Recruitment, Director of Undergraduate Studies, Associate Head of Department, Associate Head of School, Commercial Project Manager, Deputy Head of School, Director of Postgraduate Taught Programmes, Research Group Head, and one who was a former Pro Vice Chancellor.

Table 4: Former leadership and management roles

\begin{tabular}{lllllll}
\hline Answer Options (Please tick all that apply) & \multicolumn{2}{l}{ Pre-1992 } & \multicolumn{2}{l}{ Post-1992 } & \multicolumn{2}{l}{ Total } \\
\hline & $\mathbf{n}$ & $\mathbf{\%}$ & $\mathbf{n}$ & $\mathbf{\%}$ & $\mathbf{n}$ & $\mathbf{\%}$ \\
Programme Leader & 61 & 32 & 46 & 30 & 107 & 31 \\
Head of Department & 31 & 16 & 36 & 23 & 67 & 19 \\
School/department Director of Teaching and Learning & 36 & 19 & 15 & 10 & 51 & 15 \\
School/department Director of Research & 18 & 9 & 14 & 9 & 32 & 9 \\
Senior management position in organisation outside & 14 & 7 & 11 & 7 & 25 & 7
\end{tabular}




\begin{tabular}{lllllll} 
Head of School & 9 & 5 & 15 & 10 & 24 & 7 \\
School/department Director of Enterprise & 3 & 2 & 4 & 3 & 7 & 2 \\
Other & 18 & 9 & 13 & 8 & 31 & 9 \\
Answered question & 190 & 100 & 154 & 100 & 344 & 100 \\
\hline Percentage totals may not equal 100\% due to rounding & & & & & &
\end{tabular}

Percentage totals may not equal $100 \%$ due to rounding

\section{Reasons for taking on the role}

From the interviews, there were a variety of reasons given as to why individuals took on the role of Associate Dean, which tended to fall into four key areas: being asked to take it on by a senior member of staff; for the challenge of working across the University; to 'make a wider difference' to staff and students; and to develop a specific career path (away from a traditional academic 'research' career).

As well as being asked to take on the role by senior leaders, several interviewees were keen to take on a new challenge. For example, Whitney said:

And so, I decided to go for it, because I think by then, I'd been here for a very long time, possibly about ten years at that point. And I wanted something new to do really, different sorts of challenges, and I was also very aware that while my discipline was always very vibrant and interesting and changing and therefore very challenging, that it was a very small sector of higher education... So going into the Associate Dean role I was aware would give me a broader opportunity. (Whitney, pre-1992 University)

And David said that he wanted to make a real difference to as many students as possible:

I think I always, and this sounds trite it really does, but I always put the students at the centre. Their experience is crucial, their experience is for life. (David, pre1992 University)

Chris and William had decided that they would follow a managerial career route as they felt that they were not going to be successful enough as researchers. They said: 
...although I am research active I don't really think I can build a stellar career around research, I don't really see myself as a world leader in research. I mean I am known nationally and internationally, and I do get invitations to go to conferences and write books and things like that, but I don't actually think I will ever go all the way as a researcher. So, if I want to advance my career I need to think about what else I can do... (Chris, pre-1992 University)

But then as I mentioned earlier on sort of managerialism that has crept into Higher Education I found my niche there, rather than the research angle. So, it's been the managerial side, organisation, quality, all those aspects. (William - post-1992 University)

The reasons given by survey participants for taking on the role are shown in Table 5. In this question, participants were again asked to tick all options that applied. In relation to career ambitions, a finding which will be developed later in this article, 23 Associate Deans from pre-1992 institutions and 17 from post-1992 institutions (25 per cent in total) had ambitions to take on a more senior leadership position in the future.

Table 5: Reasons for taking on the role

\begin{tabular}{lllllll}
\hline Answer Options (please tick all that apply) & \multicolumn{2}{l}{ Pre-1992 } & \multicolumn{2}{l}{ Post-1992 } & \multicolumn{2}{l}{ Total } \\
\hline & $\mathbf{n}$ & $\mathbf{\%}$ & $\mathbf{n}$ & $\mathbf{\%}$ & $\mathbf{n}$ & $\mathbf{\%}$ \\
I wanted a new challenge & 55 & 22 & 32 & 21 & 87 & 21 \\
I wanted to make a wider impact at the institution & 50 & 20 & 36 & 23 & 86 & 21 \\
I wanted a more University wide role & 48 & 19 & 32 & 21 & 80 & 20 \\
I was asked to take it on by a senior member of staff & 44 & 18 & 19 & 12 & 63 & 16 \\
I have ambitions of taking on a senior leadership & 23 & 9 & 17 & 11 & 40 & 10 \\
position in the future & & & & & & \\
I wanted to 'give something back' to the institution & 19 & 8 & 11 & 7 & 30 & 7 \\
I wanted to move away from teaching & 3 & 1 & 0 & 0 & 3 & 1 \\
I wanted to move away from research & 1 & 0 & 0 & 0 & 1 & 0 \\
Other & 6 & 2 & 9 & 6 & 15 & 4 \\
Answered question & 249 & 100 & 156 & 100 & 405 & 100 \\
\hline
\end{tabular}

Percentage totals may not equal 100 due to rounding

\section{Career plans}

From the interviews, there were a range of responses to the question of 'what next?' in relation to the participants' careers and how being an Associate Dean had influenced these decisions. Several talked about the fact that there was not a clearly defined career 
path for the role. For example, Phil said:

That's a question that people often ask Associate Deans, and it'll be interesting what your research turns up about that, because it's very unclear what the career trajectory is from the role. (Phil - pre-1992 University)

For those participants who were on a fixed term role and expected to return to their departments, several commented that returning to be a 'normal' academic would be 'very difficult' because they had not kept up with their research or teaching. They also mentioned that it would be potentially problematic to return to the 'ranks' having made some difficult decisions in their role as Associate Dean. As Bruce said:

I suppose when I accepted the king's shilling and took this role as indeed any of my other colleagues on the executive did, there is this sort of snakes and ladders thing where you might find yourself back as a Senior Lecturer in the classroom. (Bruce, post-1992 University)

And Steven commented:

The next move is either up or out really, because I think I'm so far divorced from teaching and research now, it would be unfair to say to colleagues, 'Just absorb me back into the department as a principal lecturer.' It would take me three years to get back up to speed again... So, I think that's where you find yourself. (Steven, post-1992 University)

Alex highlighted how important it was to think in career terms beyond the tenure of the role:

...the most crucial thing is to work out what you're not going to do for that period and the implications of that for when you stop being Associate Dean. (Alex, pre1992 University)

Claire offered similar advice to anyone thinking of taking on the role: 
I would say to them that there is this huge black hole at the end of the time when you might stop being an associate dean and I don't know anybody who feels like they've done that right, exiting and going onto something else. So, keep your options open. (Claire, pre-1992)

In contrast, of those who were in full time promoted posts, several talked about applying for promotion. However, there was a feeling from some that applying for a Dean's role (arguably the most logical step) would be hard because they felt that they did not have enough financial experience. For example, Laura commented:

Well it's interesting. I mean, the problem with applying for a Dean's role is it's hard to demonstrate you've had financial responsibility and control. So, I think you would probably be a bit pushed to get one. (Laura, post-1992 University)

Tony felt that applying for a Pro Vice Chancellor role may be more appropriate:

If you'd asked me three years ago I'd have said I expect to be a Dean. I'm now not convinced that that is the right post for me. I think [laughter] given that this is a Dean's job more or less in not quite the name, I'm not sure that an appropriate next step would be moving into a job that is labelled Dean just for the sake of maybe a few percentage points in salary...I think in the right institution it's possible that I could be a Pro Vice Chancellor or equivalent role in a small institution, again that deputising role to the leader may be a better fit for my skills and my personality but it would have to be the right - it would probably need to be a relatively small institution for me to stand a chance of that, but I think ultimately that's probably the most likely. (Tony, post-1992 University)

Finally, some of those interviewed talked about staying in the role. For Whitney, this would allow them to consolidate their personal and professional life:

I think it depends on you personally and your drive and what your drive is. You know I thought about using it as an opportunity to prepare myself for going for a Pro Vice Chancellor role...But I thought well I have to look at my life....and I thought given two small children, not actually that old yet, actually that's rushing it. I thought I'm content to stay where I am, do things that I'm interested in doing, in 
the role, making the difference in the role and trying to balance my family life alongside that. (Whitney, pre-1992 University)

While Chris said:

I'm not very good at career planning. I tend to go with the opportunities that come my way. But I'm very much not a career person, you know I don't have a goal in mind, some people do...but I don't. I don't feel that I have to get to a certain point to feel successful, as long as I'm enjoying what I do on a day to day basis then I'm happy. (Chris, pre-1992 University)

From the survey, respondents identified a range of career plans within the next 5 years as shown in Table 6. Other plans included taking a year's sabbatical and applying for promotion to Professor.

Table 6: Career plans within next 5 years

\begin{tabular}{lllllll}
\hline Answer Options & Pre-1992 & \multicolumn{2}{l}{ Post-1992 } & \multicolumn{2}{l}{ Total } \\
\hline & $\mathbf{n}$ & $\mathbf{\%}$ & $\mathbf{n}$ & $\mathbf{\%}$ & $\mathbf{n}$ & $\mathbf{\%}$ \\
Return to my previous academic role & 27 & 27 & 4 & 6 & 31 & 19 \\
Remain in my current post & 15 & 15 & 12 & 18 & 27 & 16 \\
Seek a higher leadership and management post & 10 & 10 & 17 & 26 & 27 & 16 \\
in a different institution & & & & & & \\
Seek a higher leadership and management post & 15 & 15 & 11 & 17 & 26 & 16 \\
in my current institution & & & & & & \\
Undecided & 12 & 12 & 7 & 11 & 19 & 12 \\
Retire & 6 & 6 & 11 & 17 & 17 & 10 \\
Seek another role within Higher Education & 3 & 3 & 0 & 0 & 3 & 2 \\
Leave Higher Education for another profession & 1 & 1 & 1 & 2 & 2 & 1 \\
Other & 11 & 11 & 2 & 3 & 13 & 8 \\
Answered question & 100 & 100 & 65 & 100 & 165 & 100 \\
\hline Percentage totals may not equal 100\% because of rounding & & & & &
\end{tabular}

\section{Discussion}

As described earlier, the data from our study were cross tabulated between participants from pre and post 1992 institutions with the hope of exploring any differences between these two culturally different organisational types. However, our findings suggest that in relation to the circumstances that lead academics to becoming Associate Deans, and how it impacts on their future career plans, more similarities than differences are 
apparent between these two groups. This may well reflect the seeming recent convergence of culture and value systems between the two institutional types; this has also been found in relation to research into department heads (Floyd, 2016). This convergence can be explained by increasing isomorphism within the sector (Stensaker \& Norgard, 2001) as universities struggle to compete in an increasingly competitive market (Floyd \& Preston, 2017). Therefore, the discussion that follows is organised by addressing each of the study's research questions in turn, drawing on the study's theoretical framework outlined earlier, and drawing on the overall findings from both types of universities.

\section{What are the circumstances that lead to UK academics becoming Associate}

\section{Deans?}

\section{Learning to lead}

Our findings suggest that many of our participants had taken on prior leadership roles before becoming Associate Deans, although taking on these roles did not appear to have been carefully planned career moves. Instead, these early socialisation experiences and shifts in identity from academic to academic leader seem to have come about through key institutional changes such as restructuring. Although most moves were unplanned, the experiences appeared to be a good apprenticeship before taking on the Associate Dean role as they would have afforded them the chance to learn more of the organisational culture of their work place and the social expectations and standards, signs, language, behaviours, events and people that embody this culture (Alvesson, 2002; Trowler, 2008). Such experience would also allow them to develop important discursive leadership strategies (Fairhurst, 2008, 2009; Whittle, Housley, Gilchrist, Mueller, \& Lenney, 2015; Wodak, Kwon, \& Clarke, 2011) which include negotiation, 
persuasion, and relationship building. All these strategies have been identified as essential for Associate Deans who, it has been found, may hold leadership positions without any formal line management responsibilities or budgetary control and so need to rely on such skills in order to lead change successfully within their organisation (Floyd \& Preston, 2017).

Through taking on these roles, we suggest that our participants had developed their internal career capital by developing the skills and experiences necessary to take on more senior roles within an institution, often at the expense of their own research careers. Thus, for some academics increasing their internal career capital in relation to leadership and management may in fact decrease their external career capital (in the form of research grants and publications). This point will be discussed more fully later.

\section{Reason for taking on the role}

Several of the respondents took on the role of Associate Dean for personal reasons, such as wanting a new challenge, and ambitions of taking up a more senior leadership position in the future. These participants seemed to feel that they had increased agency (and by association internal career capital) within the social structures or 'communities' (Henkel, 2005) in which they worked and were attempting to exert this in order to take control of their own career paths. The interactive process between agency and structure is a key factor when interpreting these findings, as it has previously been suggested that human agency and individuals are now seen as the driving force behind career trajectories rather than organisations (Gordon, 2003; Svejenova, 2005). With less institutional loyalty due to the rise of New Public Management cultures of accountability and performativity within the sector, which has led to increased uncertainty in relation to job security and the traditional 'job for life', and the notion 
that in the last two decades people are developing more individually-focused career paths based on ideas of the 'boundaryless' career (Arthur \& Rousseau, 1996), it appears that these Associate Deans felt the need to ensure they took charge of their own career paths and, in turn, increase their perceived academic career capital for the future.

There were a number of participants who became Associate Deans because they were asked to take on the role by a senior member of staff. It seems that this 'tap on the shoulder' gave them the confidence with which to further develop their identities and careers as academic leaders within the institution in which they worked. Previous findings from research on department heads found that this 'vote of confidence' helped academics realise that they would be able to take on the role successfully (Floyd, 2012). Another explanation, however, is that these respondents may have felt pressurised into taking on the role because of power relation imbalances between themselves and their senior managers. This account is in line with more managerialist thinking linked to increasingly divergent values and practices between academic managers and managed academics (Winter, 2009) and suggests perhaps a less agentic approach to career decision making, more in accord with those who suggest that organisations and their associated boundaries still have a large part to play in career behaviour and associated theory development (see, for example, Inkson, Gunz, Ganesh, \& Roper, 2012; Rodrigues \& Guest, 2010).

Finally, there were also a significant number who wanted to make a wider impact or give something back to the institution linked to feelings of loyalty and traditional academic values of collegiality. These findings connect with Deem's (2000) classic notion of the 'good citizen' academic manager - one who is motivated to take on such roles by paying a perceived debt to the institution - and suggest that there are still a large number of academics who subscribe to these values and take on leadership roles 
and associated identities in order to make a difference to their institutions and have more influence beyond their immediate departmental communities. These individuals have more than likely joined the profession through a sense of 'calling' corresponding to Kaminsky and Behrend's way of thinking (2015, p. 385):

...it is possible for one to be strongly interested in a job, but not experience a calling. Calling requires individuals to be passionate toward their target career even in the face of obstacles and to draw value from their target career such that their life would have less meaning if they were to engage in other careers.

\section{How do academics see their position as Associate Dean influencing their career?}

Previous research into department heads found that research activity rather than departmental leadership experience is perceived as the most important form of academic career capital within the UK higher education field and that taking on a middle leadership position can sometimes be considered as detrimental to an academic's future career trajectory (Floyd, 2013; Floyd \& Dimmock, 2011). This situation also appears to be the case for some of the Associate Deans in this study, especially those who are on fixed term contracts. While they initially may have felt that they had developed their internal career capital through taking on the role, for some the reverse was in fact true as they had not been able to keep up with their research and teaching and therefore as one person said it was 'up or out'.

However, our findings suggest a more nuanced picture of what is valued as internal and external career capital with 35 per cent of the Associate Deans surveyed believing that they could progress to higher level positions within or outside their institutions. These findings suggest that these respondents felt they had acquired the relevant skills and experiences and associated academic career capital to progress their 
careers and identities as academic leaders and perhaps reflects a move away from seeing academic contributions as just being linked to research, mirroring Rosewell and Ashwin's (2018) call for other aspects of academic life to be valued. The increase in such roles as the Associate Dean across the UK also suggests that there are continuing changes to traditional academic career trajectories with leadership and management pathways becoming increasingly prevalent. These different pathways allow more choices for those academics who Deem famously termed 'career track managers' (2000), but also raise questions about what affect this may have on traditional academic identities, values and cultures based on collegiality and autonomy (Winter, 2009).

\section{Conclusions}

This article has explored the career trajectories of academics who become Associate Deans in UK universities. By drawing on the first national survey of Associate Deans undertaken in the UK and using a theoretical framework based on the concept of academic career capital, it offers an original and significant contribution to our knowledge in this area.

There are some clear professional implications from our research for universities to consider which include better planning and definition of the role and more thought as to how to socialise and exit individuals into and out of the role. Although the number of Associate Deans in UK universities is rising, the findings from this study suggest that more needs to be done in order to support individuals who take on such roles. This includes a need for better and more tailored support for them while in post (Preston \& Floyd, 2016) but also more organisational planning and support prior to individuals taking on the role to ensure that the best potential leaders are putting themselves forward or being chosen. In addition, it is clear that much more needs to be done in 
relation to succession planning to offset the fact that 55 per cent of those surveyed were expecting to return to their academic roles within their institution or aspiring to move onto higher level management roles within their own or other universities within the next five years.

Theoretically, our study has shown that there appears to be a continuing shift in academic career trajectories towards a more clearly defined managerial pathway for academics who wish to become and remain academic managers, and that roles such as the Associate Dean contribute to this. It also appears that the notion of internal and external academic career capital is more nuanced in this leadership group (as compared to department heads for example) with external academic career capital not solely being valued in terms of traditional research outputs. To develop this work, we suggest that future research should explore different academic leadership roles and associated career trajectories, as well as comparing and contrasting data from different countries. In addition, consideration could be given to include former Associate Deans in future studies. This would allow researchers to explore how taking on this role impacts on an academic's career over the longer term.

\section{References}

Alvesson, M. (2002). Understanding Organisational Culture. London: Sage Publications Ltd.

Angervall, P., Gustafsson, J., \& Silfver, E. (2018). Academic career: on institutions, social capital and gender. Higher Education Research \& Development, 37(6), 1095-1108. doi:10.1080/07294360.2018.1477743

Arthur, M. B., \& Rousseau, D. M. (Eds.). (1996). The Boundaryless Career: A New Employment Principle for a New Organizational Era. Oxford: Oxford University Press.

Bourdieu, P. (1984). Distinction - A Social Critique of the Judgement of Taste. Abingdon, Oxon: Routledge.

Bourdieu, P. (1988). Homo Academicus. Cambridge: Polity Press.

Bourdieu, P. (1998). Practical Reason - On the Theory of Action. Oxford: Blackwell Press.

Bryman, A. (2012). Social Research Methods. Oxford: Oxford University Press. 
Court, S. (1999). Negotiating the Research Imperative: The Views of UK Academics on their Career Opportunities. Higher Education Quarterly, 53(1), 65-87.

Cresswell, J. (2014). Research Design (fourth ed.). London: Sage.

Deem, R. (2000). "New Managerialism" and the Management of UK Universities, End of Award Report on the Findings of an Economic and Social Research Council Funded Project Oct. 1998-Nov.2000. ESRC award number R000 237661. Retrieved from

Fairhurst, G. (2008). Discursive Leadership: A Communication Alternative to Leadership Psychology Management Communication Quarterly, 21(4), 510-521.

Fairhurst, G. (2009). Considering context in discursive leadership research. Human Relations, 62(11), 1607-1633. doi:doi:10.1177/0018726709346379

Floyd, A. (2012). 'Turning points': The personal and professional circumstances that lead academics to become middle managers. Educational Management Administration and Leadership, 40(2), 272-284. doi:10.1177/1741143211427980

Floyd, A. (2013). Narrative of academics who become department heads in a UK university. In L. Gornall, C. Cook, L. Daunton, J. Salisbury, \& B. Thomas (Eds.), Academic Working Lives: Experience, Practice and Change (pp. 86-93). London: Bloomsbury.

Floyd, A. (2016). Supporting Academic Middle Managers in Higher Education: Do We Care? Higher Education Policy, 29(2), 167-183. doi:10.1057/hep.2015.11

Floyd, A., \& Dimmock, C. (2011). 'Jugglers', 'copers' and 'strugglers': Academics' perceptions of being a HoD in a post-1992 UK university and how it influences their future careers. Journal of Higher Education Policy and Management, 33(4), 387-399. doi:10.1080/1360080X.2011.585738

Floyd, A., \& Preston, D. (2017). The role of the associate dean in UK universities: distributed leadership in action? Higher education, 75(5), 925-943. doi:10.1007/s10734-017-0178-1

Gordon, G. (2003). University Roles and Career Paths: Trends, Scenarios and Motivational Challenges. Higher Education Management and Policy, 15(3), 89103.

Henkel, M. (2005). Academic identity and autonomy in a changing policy environment. Higher education, 49(1-2), 155-176.

Hu, W. C. Y., Thistlethwaite, J. E., Weller, J., Gallego, G., Monteith, J., \& McColl, G. J. (2015). 'It was serendipity': a qualitative study of academic careers in medical education. Medical Education, 49(11), 1124-1136. doi:10.1111/medu.12822

Inkson, K., Gunz, H., Ganesh, S., \& Roper, J. (2012). Boundaryless Careers: Bringing Back Boundaries. Organization Studies, 33(3), 323-340. doi:10.1177/0170840611435600

Jepsen, D. M., Sun, J. J.-M., Budhwar, P. S., Klehe, U.-C., Krausert, A., Raghuram, S., \& Valcour, M. (2014). International academic careers: Personal reflections. International Journal of Human Resource Management, 25(10), 1309-1326. doi:10.1080/09585192.2013.870307

Kaminsky, S. E., \& Behrend, T. S. (2015). Career Choice and Calling:Integrating Calling and Social Cognitive Career Theory. Journal of Career Assessment, 23(3), 383-398. doi:10.1177/1069072714547167

Lichtman, M. (2013). Qualitative Research in Education: A User's Guide (Third ed.). Thousand Oaks, California: Sage. 
Liénard, J. F., Achakulvisut, T., Acuna, D., \& David, S. (2018). Intellectual synthesis in mentorship determines success in academic careers. Nature Communications, 9(1), 1-13. doi:10.1038/s41467-018-07034-y

Pepper, C., \& Giles, W. (2015). Leading in middle management in higher education. Management in Education, 29(2), 46-52.

Petersen, A. M., Fortunato, S., Pan, R. K., Kaski, K., Penner, O., Rungi, A., . . . Pammolli, F. (2014). Reputation and impact in academic careers. Proceedings of the National Academy of Sciences, 111(43), 15316-15321. doi:10.1073/pnas.1323111111

Petersen, A. M., Riccaboni, M., Stanley, H. E., \& Pammolli, F. (2012). Persistence and uncertainty in the academic career. Proceedings of the National Academy of Sciences, 109(14), 5213-5218. doi:10.1073/pnas.1121429109

Preston, D., \& Floyd, A. (2016). Supporting the Role of Associate Dean in Universities: an Alternative Approach to Management Development. Higher Education Quarterly, 70(3), 264-280. doi:10.1111/hequ.12099

Preston, D., \& Price, D. (2012). 'I see it as a phase: I don't see it as the future': academics as managers in a UK university Journal of Higher Education Policy and Management 34(4), 409-419.

Rodrigues, R. A., \& Guest, D. (2010). Have careers become boundaryless? Human Relations, 63(8), 1157-1175. doi:10.1177/0018726709354344

Rosewell, K., \& Ashwin, P. (2018). Academics' perceptions of what it means to be an academic. Studies in Higher Education. doi:10.1080/03075079.2018.1499717

Sayler, M. F., Pedersen, J., Smith, M. C., \& Cutright, M. (2017). Hidden leaders: results of the national study of associate deans. Studies in Higher Education. doi:10.1080/03075079.2017.1418309

Stensaker, B., \& Norgard, J. D. (2001). Innovation and isomorphism: A case-study of university identity struggle 1969-1999. Higher education, 42, 473-492.

Svejenova, S. (2005). "The Path with the Heart": Creating the Authentic Career. Journal of Management Studies, 42(5), 947-974.

Trowler, P. (2008). Cultures and Change in Higher Education Basingstoke: Palgrave Macmillan.

van Balen, B., van Arensbergenb, P., van der Weijdenc, I., \& van den Besselaar, P. (2012). Determinants of Success in Academic Careers. Higher Education Policy, 25, 313-334.

Whittle, A., Housley, W., Gilchrist, A., Mueller, F., \& Lenney, P. (2015). Category predication work, discursive leadership and strategic sensemaking. Human Relations, 68(3), 377-407. doi:doi:10.1177/0018726714528253

Winter, R. (2009). Academic manager or managed academic? Academic identity schisms in higher education. Journal of Higher Education Policy and Management, 31(2), 121-131.

Wodak, R., Kwon, W., \& Clarke, I. (2011). 'Getting people on board': Discursive leadership for consensus building in team meetings. Discourse \& Society, 22(5), 592-644. doi:doi:10.1177/0957926511405410 